\title{
(C) OPEN ACCESS \\ Clopidogrel non-responsiveness in patients undergoing percutaneous coronary intervention using the VerifyNow test: frequency and predictors
}

\author{
Israa Fadhil Yaseen, ${ }^{1}$ Hasan Ali Farhan, ${ }^{1,2}$ Hassan Mohamed Abbas $^{3}$
}

'Department of Cardiology, Baghdad Teaching Hospital, Medical City, Baghdad, Iraq ${ }^{2}$ Department of Internal Medicine, Al-Kindy College of Medicine, University of Baghdad, Baghdad, Iraq ${ }^{3}$ Department of Clinical Pharmacy, Baghdad Teaching Hospital, Medical City, Baghdad, Iraq

\section{Correspondence to} Dr Israa Fadhil Yaseen Department of Cardiology, Cardiac Catheterization Center, Medical City, Baghdad 61253, Iraq; pharm18i@yahoo.com

Received 22 July 2017 Revised 21 October 2017 Accepted 31 October 2017 Published Online First 18 November 2017

EAHP Statement 4: Clinical Pharmacy Services. EAHP Statement 5: Patient Safety and Quality Assurance. EAHP Statement 6: Education and Research

\begin{abstract}
Objectives Stent thrombosis and death after percutaneous coronary intervention (PCI) can be caused by a phenomenon known as clopidogrel non-responsiveness which has been shown to occur in approximately $5 \%-44 \%$ of patients. We investigated the responsiveness of clopidogrel in an Iraqi series of cases. Our aim was to determine for the first time the frequency and predictors of clopidogrel non-responsiveness among Iraqi patients with ischaemic heart disease undergoing PCl.
\end{abstract}

Methods The study was conducted at the Cardiac Catheterization Center, Baghdad Teaching Hospital, Medical City, from January to May 2014, and included patients who presented for $\mathrm{PCl}$. A platelet aggregation test was performed for those patients using the VerifyNow system.

Results A total of 115 patients (mean age: $58.3 \pm 10.1$ years; male sex: $73.9 \%$ ) were included in the study. $18.3 \%$ of the study population were clopidogrel non-responders, which was comparable with the results of a Chinese study $(20.28 \%, P=0.796)$ but contrasted with other reports from Jordan, Brazil and Thailand. The major independent predictive factor for non-responsiveness in our report was diabetes mellitus (OR 5.96, 95\% Cl 2.23 to $13.71 ; P=0.001$ ), followed by hypertension (OR 4.135, $\mathrm{P}=0.035)$, obesity (OR 3.44, $\mathrm{P}=0.037)$ and male sex (OR 3.039, $\mathrm{P}=0.045)$. Previous use of clopidogrel (OR 0.17, $\mathrm{P}=0.02)$ and younger age (OR $0.72, \mathrm{P}=0.026)$ were identified as protective factors.

Conclusions In this study, $18.3 \%$ of patients were non-responders to clopidogrel and the major independent predictive factors for non-responsiveness were diabetes mellitus, hypertension, obesity and male sex.

\section{INTRODUCTION}

Dual antiplatelet therapy, including aspirin given with a thienopyridine inhibitor such as clopidogrel, is the standard treatment for preventing stent thrombosis in patients undergoing percutaneous coronary intervention (PCI). ${ }^{1-3}$ Coronary stent thrombosis is rare but is one of the most serious complications following $\mathrm{PCI}^{2-4}$ Clopidogrel antagonises the ADP receptor that acts on the purinergic receptors, including P2Y12, which are responsible for the prolonged activation and aggregation of platelets. ADP has a significant role in arterial thrombosis and stent thrombosis. ${ }^{5-9}$ Despite receiving dual antiplatelet therapy, some patients still experience stent thrombosis due to clopidogrel non-responsiveness, which occurs in approximately $5 \%-44 \%$ of patients..$^{1}{ }^{2}$ Platelet activity after the administration of clopidogrel can be measured using one of the platelet aggregation tests. ${ }^{1}$ Although these tests are not recommended for routine use, they are sometimes considered in patients at high risk for poor clinical outcomes after PCI, such those with unprotected left main stem PCI involving bifurcation. ${ }^{10}$

The VerifyNow test is used to assess the patient's platelet reactivity to antiplatelet medications such as aspirin, clopidogrel and GP IIb/IIIa inhibitors. It is automated and standardised, is rapid, simple and accurate, and does not require skilled personnel. ${ }^{4}$

We investigated the responsiveness of clopidogrel in an Iraqi series of patients using the VerifyNow test. To our knowledge, this is the first report to assess Iraqi patients in this regard.

\section{METHODS}

\section{Study design and patients}

We conducted a prospective single-centre study of patients with ischaemic heart disease (IHD) who presented for PCI to the Cardiac Catheterization Center of Baghdad Teaching Hospital, Medical City, between January and May 2014.

All patients were given clopidogrel $(600 \mathrm{mg})$ and aspirin $(300 \mathrm{mg})$ orally. The clopidogrel loading dose was administered under the supervision of specialised nurses at the centre and double-checked by the clinical pharmacy resident to ensure proper administration before PCI was performed. In addition, all patients underwent a complete blood count and renal function test.

Patients were excluded from the study if they had a clopidogrel and/or aspirin contraindication, had received IIb/IIIa inhibitor within 10 days before the study, or had a haematological disorder (eg, polycythemia vera, thrombocytopenia).

The study was approved by the Research Ethics Committee of the Iraqi Board for Medical Specializations, and performed in accordance with the ethical standards of the Declaration of Helsinki. In addition, all patients signed an informed consent form before participating in the study.

\section{The VerifyNow system}

The VerifyNow system (Accumetrics, San Diego, CA, USA; serial no. 5774) was used to measure responsiveness to clopidogrel. The results were reported in P2Y12 reaction units (PRU). Cardiologists performed PCI in responders (ie, PRU $\leq 208$ ). However, the cardiologist either postponed the procedure or immediately administered a $60 \mathrm{mg}$ 
loading dose of prasugrel (based on age, weight and history of transient ischaemic attack) to patients with PRU > 208 (ie, non-responders). Following prasugrel administration, PCI was performed after $30 \mathrm{~min}$ to 2 hours using a drug-eluting stent.

\section{Blood sample collection}

Blood was drawn from the antecubital vein of each patient for the VerifyNow P2Y12 assay before PCI using 21-gauge needles and two collecting tubes. The first vacuum tube containing $5 \mathrm{~mL}$ of collected blood was discarded; this blood was not used for the platelet function test to avoid unwanted platelet activation. Blood was collected for testing in a second $2 \mathrm{~mL}$ vacutainer tube containing $3.2 \%$ sodium citrate. This tube was then gently inverted at least five times to completely mix the contents. The tube was left for $10 \mathrm{~min}$ to 4 hours before being used in the device. $^{11}$

\section{Statistical analysis}

Patient data were analysed using the Statistical Package for Social Sciences (SPSS), version 22 (IBM, USA). Body mass index was estimated using the Du Bois equation. ${ }^{12}$ The estimated glomerular filtration rate was estimated using the Modification of Diet in Renal Disease study equation. ${ }^{13}$ Descriptive statistics are presented as the mean, SD, frequencies (number) and proportions (\%). The $\chi^{2}$ and Fisher's exact test were used alternately to compare frequencies when applied to estimate the relationship between categorical variables. Student's t-test was used to compare the means between two continuous variables (haematological and biochemical). The multiple logistic regression (binary) test was used to assess the significance of the association between non-responsiveness and potential predictors. The level of significance was set at $\mathrm{P}<0.05$.

\section{RESULTS}

Overall, 120 patients were initially included in the study. Five of these patients were excluded: one was diagnosed with polycythemia vera during investigation before PCI, one had thrombocytopenia, one underwent peripheral angiography, and two refused the platelet aggregation responsiveness test. Thus, 115 patients were enrolled. The descriptive statistics and results of the univariate analysis are shown in table 1 . Patients were categorised into two groups using a PRU of 208 as the cut-off point: 21 patients $(18.3 \%)$ had a PRU > 208 and the remaining 94 $(81.7 \%)$ had a PRU $\leq 208$.

The results of the multiple regression analysis are shown in table 2. Diabetes $(\mathrm{OR}=5.96, \mathrm{P}<0.001)$, hypertension $(\mathrm{OR}=4.14, \mathrm{P}=0.035)$, obesity $(\mathrm{OR}=3.44, \mathrm{P}=0.037)$ and male $\operatorname{sex}(\mathrm{OR}=3.03, \mathrm{P}=0.045)$ were associated with a higher risk of patient non-responsiveness to clopidogrel. However, younger age $(\mathrm{OR}=0.72, \mathrm{P}=0.026)$ and previous use of clopidogrel $(\mathrm{OR}=0.17, \mathrm{P}=0.021)$ were associated with a lower risk of non-responsiveness. On the other hand, previous use of clopidogrel and younger age were protective factors after adjustment for other variables. Other factors, including smoking, previous IHD, previous PCI, statin use, type of statin used, and estimated glomerular filtration rate showed no significant association with non-responsiveness.

\section{DISCUSSION}

Clopidogrel non-responsiveness is a matter of concern worldwide. To the best of our knowledge, this study is the first in Iraq to determine the rate of and predictive factors for clopidogrel non-responsiveness among patients with IHD. Using the VerifyNow test, we estimated that the rate of non-responsiveness was $18.3 \%$ among our patients after they had received a loading dose of clopidogrel and before they underwent PCI.

Table 1 Patient characteristics and univariate analysis results

\begin{tabular}{|c|c|c|c|c|}
\hline Clinical demographic characteristics & All patients, $\mathrm{n}(\%)$ & Non-responders (PRU >208; $\mathrm{n}=21$ ), $\%$ & Responders (PRU $\leq 208 ; n=94), \%$ & $P$ value \\
\hline Age, years $(m e a n \pm S D)$ & $58.3 \pm 10.1$ & $59.6 \pm 8.2$ & $58.0 \pm 10.5$ & 0.43 \\
\hline Men & $85(73.9)$ & 57.1 & 77.7 & 0.061 \\
\hline BMI $\left(\mathrm{kg} / \mathrm{m}^{2}\right)$ & $29.6 \pm 5.8$ & $31.8 \pm 6.1$ & $29.1 \pm 5.6$ & 0.03 \\
\hline $\mathrm{eGFR}\left(\mathrm{mL} / \mathrm{min} / 1.73 \mathrm{~m}^{2}\right)$ & & $1.02 \pm 0.51$ & $0.88 \pm 0.24$ & 0.071 \\
\hline Haemoglobin (g/dL) & & $12.28 \pm 2.17$ & $14.33 \pm 1.95$ & $<0.001$ \\
\hline HTN & $69(60.0)$ & 57.1 & 60.6 & 0.81 \\
\hline Diabetes & $48(41.7)$ & 71.4 & 35.1 & 0.003 \\
\hline Smoking & $24(20.9)$ & 19 & 21.3 & 0.92 \\
\hline Previous IHD & $47(40.9)$ & 33.3 & 42.6 & 0.59 \\
\hline Previous $\mathrm{PCl}$ & $28(24.3)$ & 0 & 29.8 & 0.003 \\
\hline \multicolumn{5}{|l|}{ Medications used } \\
\hline Aspirin & $101(87.8)$ & 85.7 & 88.3 & 0.72 \\
\hline Clopidogrel & $88(76.5)$ & 52.4 & 81.9 & 0.008 \\
\hline Beta-blocker & $84(73.0)$ & 76.2 & 72.3 & 0.8 \\
\hline ACEI/ARB & $58(50.4)$ & 52.4 & 50 & 1 \\
\hline Statin & $101(87.8)$ & 71.4 & 91.5 & 0.021 \\
\hline Atorvastatin & $66(57.4)$ & 42.9 & 60.6 & 0.011 \\
\hline Rosuvastatin & $31(27.0)$ & 23.8 & 27.7 & 0.05 \\
\hline Fluvastatin & $2(1.7)$ & 4.8 & 1.1 & 0.84 \\
\hline Simvastatin & $2(1.7)$ & 0 & 2.1 & 0.24 \\
\hline PPI & $12(10.4)$ & 9.5 & 10.6 & 0.62 \\
\hline Insulin & $10(8.7)$ & 9.5 & 8.5 & 0.58 \\
\hline
\end{tabular}

$\mathrm{ACEl}$, angiotensin-converting enzyme inhibitor; ARB, angiotensin receptor blocker; BMI, body mass index; eGFR, estimated glomerular filtration rate; HTN, hypertension; IHD, ischaemic heart disease; PCI, percutaneous coronary intervention; PPI, proton pump inhibitor; PRU, P2Y12 reaction unit. 
Table 2 Results of the multiple logistic regression test for patient non-responsiveness to clopidogrel (PRU >208)

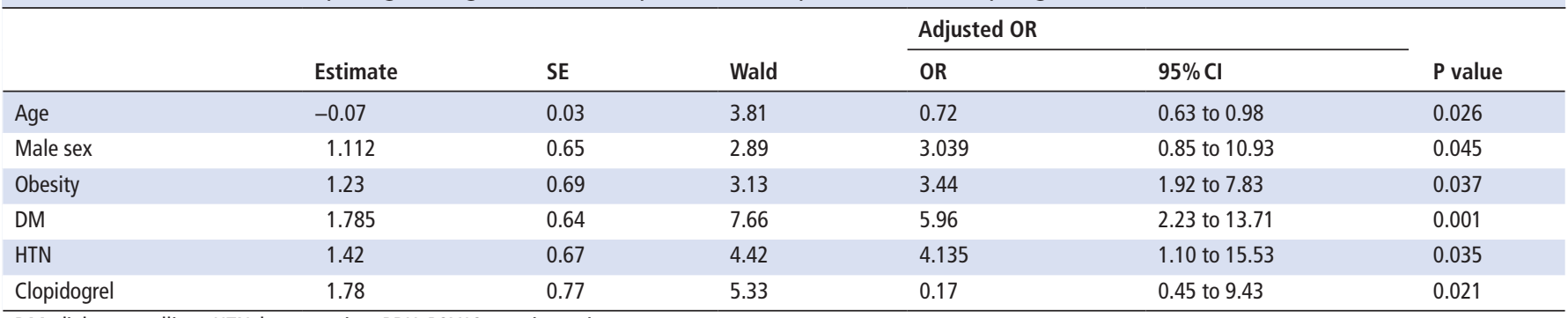

DM, diabetes mellitus; HTN, hypertension; PRU, P2Y12 reaction unit.

The prevalence of intermediate or poor metabolism of clopidogrel with the resultant non-responsiveness, seems to be higher in Asian populations due to genetic polymorphisms associated with clopidogrel resistance. A low incidence of approximately $3 \%$ has been found in Caucasian populations, while rates varying from $18 \%-23 \%$ up to nearly $70 \%$ have been reported in Asian communities. This might be related to the common genetic variants of the hepatic enzyme responsible for clopidogrel metabolism (CYP2C19) in Asian populations. ${ }^{14-16}$ The rate of clopidogrel non-responsiveness in our study was similar to previous findings, and comparable with that seen among Chinese subjects $(20.28 \%, \mathrm{P}=0.796) .{ }^{17}$ On the other hand, Al-Azzam et al reported a significantly higher incidence of clopidogrel non-responsiveness among Jordanian subjects compared with our patients $(32 \%, \mathrm{P}=0.006) .{ }^{18}$ However, they used a test other than the VerifyNow system to measure clopidogrel responsiveness, which might have affected their results. ${ }^{18}$ Compared with our data, a significantly higher ratio of clopidogrel non-responsiveness was reported among Brazilian and Thai patients, with incidences of $38.5 \%$ and 50\%, respectively (both $\mathrm{P}<0.001$ ). ${ }^{19} 20$ In addition to genetic variability, multiple other factors can influence clopidogrel non-responsiveness, such as technical issues, type of instrument used, or patient adherence to clopidogrel. ${ }^{1420}$

In this study, the major independent predictive factor for clopidogrel non-responsiveness was diabetes mellitus. Our findings agreed with results from China, ${ }^{17}$ Poland, ${ }^{21}$ Italy $^{22}$ and America. ${ }^{23}$

There are several possible mechanisms for clopidogrel non-responsiveness in patients with diabetes, such as increasing platelet turnover with increasing exposure to $\mathrm{ADP},{ }^{17}$ elevation of plasma fibrinogen with a possible direct interaction with GP IIb/IIIa on the platelet surface leading to platelet aggregation, and decreased clopidogrel responsiveness. ${ }^{22}$ In addition, increased production of platelet agonists such as epinephrine and thrombin, promoted platelet aggregation and activation of circulating platelets. ${ }^{22} 24$ However, no association between clopidogrel non-responsiveness and diabetes was reported by other studies. ${ }^{1825}$ One of those studies suggested that responsiveness depended on the ability of insulin to suppress important regulatory proteins involved in blood clotting, such as purinergic receptor P2Y G-protein coupled 12 (P2Y12). ${ }^{18}$

Other independent predictors in this study included hypertension, obesity and male sex. Park et al reported that hypertension was also significantly associated with clopidogrel non-responsiveness in a Korean case series. ${ }^{26}$ In contrast, other studies have shown no association between hypertension and clopidogrel non-responsiveness, ${ }^{18} 25$ which might be due to tight blood pressure control as mentioned previously. ${ }^{18}$ Obesity was also significantly associated with clopidogrel non-responsiveness in some reports, ${ }^{17} 21$ although no relationship was observed by Ahn et $\mathrm{al}^{25}$ The lack of an association between obesity and clopidogrel non-responsiveness could be related to absence of the metabolic syndrome, as shown by Kubica et al. ${ }^{21}$ Some studies demonstrated that female sex was a predictive factor for clopidogrel non-responsiveness. ${ }^{18} 2326$ However, our study demonstrated that male sex was an independent predictive factor for non-responsiveness, but this might have been due to the higher number of men enrolled in this study. Two protective factors against clopidogrel non-responsiveness were found in this study: prior use of clopidogrel as maintenance therapy, and young age. Several studies, including the current report, have reported that old age is a risk factor for non-responsiveness, ${ }^{17} 232526$ while Al-Azzam et al found no significant relationship. ${ }^{18}$

A low haemoglobin level was significantly associated with clopidogrel non-responsiveness in the univariate analysis, which result was different from the findings of a Korean study. ${ }^{26}$ Statin use of atorvastatin only was significantly associated with a lower rate of clopidogrel non-responsiveness in the univariate analysis. American and German studies showed that the lipophilic atorvastatin (CYP3A4 inhibitor) competitively inhibits the metabolism and activation of clopidogrel. ${ }^{27} 28$ However, a Swedish study showed that atorvastatin did not attenuate the inhibitory effect of clopidogrel, in contrast to rosuvastatin (non-CYP3A4 metabolised), but a dose-dependent aetiology could explain such variation. $^{29}$

Notably, in our study smoking was not associated with clopidogrel responsiveness as in several studies, ${ }^{20} 2325$ however, the smoker's paradox was observed by Wang et $a l^{17}$ and Park et $a{ }^{26}{ }^{26}$ Genetic factors possibly play a role in the East Asian paradox. ${ }^{30}$ Factors such as previous PCI, previous IHD and disturbed renal function in our study were not associated with clopidogrel non-responsiveness.

\section{Limitations}

The limitations of this study include the lack of clinical follow-up for outcome and complications such as stent thrombosis or subsequent myocardial infarction rates, in addition to the lack of a genetic study for further evaluating clopidogrel non-responder patients.

\section{CONCLUSIONS}

The rate of clopidogrel non-responsiveness in the current study was $18.3 \%$ among Iraqi patients with IHD undergoing PCI. Diabetes mellitus was the main independent predictive factor for clopidogrel non-responsiveness. Hypertension, obesity and male sex were other independent predictive factors. Previous use of maintenance clopidogrel and younger age were protective factors against clopidogrel non-responsiveness. It is essential that patients with the above independent predictive variables are re-evaluated regarding platelet function before undergoing PCI. 


\section{What this paper adds}

What is already known on this subject

- Clopidogrel non-responsiveness (CNR) may lead to acute stent thrombosis and death in patients undergoing percutaneous coronary intervention.

- The prevalence of and predictive factors for CNR vary among different populations.

\section{What this study adds}

- This is the first study in Iraq to estimate the prevalence of and predictive factors for CNR.

- Unlike previous studies, our report showed that male sex is a predictive factor for CNR.

- Our study confirmed that diabetes mellitus is the most important predictive factor for CNR.

Acknowledgements The authors appreciate the help of Associate Professor Dr Lika'a Fasih Y. Al-Kzayer (Shinshu University School of Medicine, Matsumoto, Nagano, Japan) for medical writing assistance. We would also like to thank the interventional cardiologist Dr Hussein H. Al-Kinzawi (Al-Nasiriyah Heart Center, Nasiriyah, Thi-Qar, Iraq) and nurse Hussein A. Abbas (Cardiac Catheterization Center Baghdad Teaching Hospital, Medical City, Baghdad, Iraq) for their technical support.

Competing interests None declared.

Provenance and peer review Not commissioned; externally peer reviewed.

Open access This is an open access article distributed in accordance with the Creative Commons Attribution Non Commercial (CC BY-NC 4.0) license, which permits others to distribute, remix, adapt, build upon this work non-commercially, and license their derivative works on different terms, provided the original work is properly cited and the use is non-commercial. See: http://creativecommons.org/ licenses/by-nc/4.0/

(C) European Association of Hospital Pharmacists (unless otherwise stated in the text of the article) 2019. All rights reserved. No commercial use is permitted unless otherwise expressly granted.

\section{REFERENCES}

1 Trujillo CT, Nolan EP, Angina C. et al In: Alldredge KB, Corelli LR, Ernst EM, Koda-Kimble and young's applied therapeutics: the clinical use of drugs. 10th ed. Philadelphia, USA: Lippincott Williams \& Wilkins, 2013.

2 Buchanan GL, Basavarajaiah S, Chieffo A, et al. Stent thrombosis: incidence, predictors and new technologies. Thrombosis 2012;2012:956-62.

3 Godschalk TC, Hackeng CM, Ten Berg JM. Towards personalized medicine based on platelet function testing for stent thrombosis patients. Thrombosis 2012. doi: 10.1155/2012/617098. [Epub ahead of print 25 Dec 2012].

4 Vlachojannis GJ, Dimitropoulos G, Alexopoulos D. Clopidogrel resistance: current aspects and future directions. Hellenic J Cardiol 2011;52:236-45.

5 Gurbel PA, Bliden KP, Butler K, et al. Randomized double-blind assessment of the onset and offset of the antiplatelet effects of ticagrelor versus clopidogrel in patients with stable coronary artery disease: the ONSET/OFFSET study. Circulation 2009;120:2577-85.

6 Tselepis AD, Gerotziafas G, Andrikopoulos G, et al. Mechanisms of platelet activation and modification of response to antiplatelet agents. Hellenic J Cardiol 2011;52:128-40.

7 Price MJ. Bedside evaluation of thienopyridine antiplatelet therapy. Circulation 2009;119:2625-32.

8 Capodanno D, Ferreiro JL, Angiolillo DJ. Antiplatelet therapy: new pharmacological agents and changing paradigms. J Thromb Haemost 2013;11 (Suppl 1):316-29.
9 Cattaneo M. New P2Y(12) inhibitors. Circulation 2010;121:171-9.

10 Aradi D, Storey RF, Komócsi A, et al. Expert position paper on the role of platelet function testing in patients undergoing percutaneous coronary intervention. Eur Heart J 2014:35:209-15.

11 Verify now P2Y12 platelet reactivity test instructions for use. http://www.accriva.com/ uploads/literature/vn1009en-web_00.pdf (accessed on 16 Mar 2017).

12 National Institutes of Health, National Heart, Lung, and Blood Institute. Calculate your body mass index. National Institutes of Health, National Heart, Lung, and Blood Institute. http://www.nhlbi.nih.gov/health/educational/lose_wt/BMI/bmi-m.htm (accessed 29 Jan 2016).

13 National Kidney Foundation. GFR Calculator. https://www.kidney.org/ professionals/kdogi/gfr calculator?scrType $=\mathrm{mg} \&$ gender $=$ female\&race $=0$ ther $\&$ arrays $=$ yes\&adjustment $=$ no\&heightType=in\&weightType=pounds $($ accessed 29 Jan 2016)

14 Hasan MS, Basri HB, Hin LP, et al. Genetic polymorphisms and drug interactions leading to clopidogrel resistance: why the Asian population requires special attention. Int J Neurosci 2013;123:143-54

15 Umemura K, Furuta T, Kondo K. The common gene variants of CYP2C19 affect pharmacokinetics and pharmacodynamics in an active metabolite of clopidogrel in healthy subjects. J Thromb Haemost 2008;6:1439-41.

16 Uchiyama S. Clopidogrel resistance: identifying and overcoming a barrier to effective antiplatelet treatment. Cardiovasc Ther 2011;29:e100-e111.

17 Wang L, Wang X, Chen F. Clopidogrel resistance is associated with long-term thrombotic events in patients implanted with drug-eluting stents. Drugs $R D$ 2010;10:219-24

18 Al-Azzam SI, Alzoubi KH, Khabour OF, et al. Factors that contribute to clopidogrel resistance in cardiovascular disease patients: environmental and genetic approach. Int J Clin Pharmacol Ther 2013;51:179-86.

19 Silva FB, Almeida Junior GL, Neno A, et al. Resistance to clopidogrel: prevalence and associate variables. Arq Bras Cardiol 2012;99:1135-41.

20 Pussadhamma B, Kiatchoosakun S, Wongvipaporn C. The prevalence of clopidogrel resistance in reinfarction and recurrent myocardial infarction: a single-centre preliminary report. Srinagarind Med J 2014;29:357-64.

21 Kubica A, Obońska K, Kasprzak M, et al. The impact of metabolic syndrome on the antiplatelet effect of clopidogrel and aspirin in patients with acute coronary syndrome. Fol Medica Cop 2014;2:66-72.

22 Mangiacapra F, Patti G, Peace A, et al. Comparison of platelet reactivity and periprocedural outcomes in patients with versus without diabetes mellitus and treated with clopidogrel and percutaneous coronary intervention. Am J Cardiol 2010;106:619-23.

23 Sharma RK, Erickson SW, Sharma R, et al. Platelet function testing to predict hyporesponsiveness to clopidogrel in patients with chest pain seen in the emergency department. Vasc Health Risk Manag 2013;9:187-93.

24 Franchi F, Angiolillo DJ. Novel antiplatelet agents in acute coronary syndrome. Nat Rev Cardiol 2015;12:30-47.

25 Ahn SG, Lee SH, Yoon JH, et al. Different prognostic significance of high on-treatment platelet reactivity as assessed by the VerifyNow P2Y12 assay after coronary stenting in patients with and without acute myocardial infarction. JACC Cardiovasc Interv 2012;5:259-67.

26 Park KW, Park JJ, Jeon KH, et al. Enhanced clopidogrel responsiveness in smokers: smokers' paradox is dependent on cytochrome P450 CYP1A2 status. Arterioscler Thromb Vasc Biol 2011;31:665-71.

27 Lau WC, Waskell LA, Watkins PB, et al. Atorvastatin reduces the ability of clopidogrel to inhibit platelet aggregation: a new drug-drug interaction. Circulation 2003;107:32-7.

28 Neubauer H, Günesdogan B, Hanefeld C, et al. Lipophilic statins interfere with the inhibitory effects of clopidogrel on platelet function--a flow cytometry study. Eur Heart J 2003;24:1744-9.

29 Malmström RE, Ostergren J, Jørgensen L, et al. Influence of statin treatment on platelet inhibition by clopidogrel - a randomized comparison of rosuvastatin, atorvastatin and simvastatin co-treatment. J Intern Med 2009;266:457-66.

30 Levine GN, Jeong YH, Goto S, et al. Expert consensus document: World Heart Federation expert consensus statement on antiplatelet therapy in East Asian patients with ACS or undergoing PCI. Nat Rev Cardiol 2014;11:597-606. 